\title{
Column Classification/Characterisation of Strong Cation Exchange Phases for the Liquid Chromatographic Analysis of Small Molecular Weight Bases
}

\author{
Jennifer K. Field ${ }^{1} \cdot$ Ashleigh Bell $^{1}$ - Ifigeneia Christopoulou ${ }^{1} \cdot$ Patrik Petersson $^{2} \cdot$ Paul D. Ferguson $^{3}$. \\ Melvin R. Euerby ${ }^{1,4}$ (1)
}

Received: 30 April 2020 / Revised: 28 July 2020 / Accepted: 5 August 2020 / Published online: 20 August 2020

(c) The Author(s) 2020

\begin{abstract}
A simple, rapid and robust protocol for the characterisation of strong cation exchange columns for the analysis of small molecular weight bases is described. A range of ten different phases were characterised, and the resultant selectivity and retention factors analysed using Principal Component Analysis. The score plots for the first and second principal components described $83 \%$ of the variability within the dataset. Score plots highlighted the large chromatographic differences observed between the phases, the validity of which was established using a larger range of bases. All the strong cation exchange materials demonstrated a synergistic mixed mode (i.e. ion exchange and hydrophobic) retention mechanism. Principal Component Analysis also highlighted the potential difficulty in locating suitable strong cation exchange "back-up" columns for the analysis of small molecular weight bases in that the characterised columns all displayed very different selectivities. The robustness of the protocol was confirmed by a factorial design experiment.
\end{abstract}

Keywords Strong cation exchange stationary phases - Column characterisation · Principal Component Analysis . Robustness testing $\cdot$ Factorial design $\cdot$ Small molecular weight bases

\section{Introduction}

Over the last 20 years, considerable efforts have been made to assist the chromatographer in selecting reversed-phase LC (RP-LC) columns for various purposes such as identifying ones with differing chromatographic selectivity for method development proposes and those with very similar

Electronic supplementary material The online version of this article (https://doi.org/10.1007/s10337-020-03943-7) contains supplementary material, which is available to authorized users.

Melvin R. Euerby

Mel.euerby@shimadzu.co.uk

1 Strathclyde Institute of Pharmacy and Biomedical Sciences, University of Strathclyde, Glasgow G4 ORE, UK

2 Novo Nordisk A/S, Novo Nordisk Park, 2760 Måløv, Denmark

3 AstraZeneca, Silk Road Business Park, Macclesfield SK10 2NA, UK

4 Shimadzu UK, Milton Keynes, Buckinghamshire MK12 5RD, UK selectivity and retention as equivalent columns for "back up" purposes. This has been accomplished by the establishment of column characterisation databases which are freely available on the internet allowing the chromatographer to search the databases using predefined selection criteria. The largest RP-LC databases are based on the Snyder's Hydrophobic Subtraction Model [1] and the extended Tanaka protocols developed by Euerby et al. [2] which can be found in the USP PQRI and the ACD databases, respectively [3-5]. Publications have also been made to characterise stationary phases for hydrophilic interaction (HILIC) [6] and supercritical fluid chromatography (SFC) [7]. In comparison, to date, there has been no attempt to produce a column characterisation protocol/database for strong cation exchange (SCX) columns suitable for the analysis of small molecular weight bases. While hydrophobic bases can be successfully chromatographed using RP columns, hydrophilic bases are often poorly retained on RP columns and SCX columns can be employed to provide retention [8-11]. Given the dearth of information provided by the stationary phase manufacturers regarding SCX phase properties, the poorly understood chemistry 
associated with them (i.e. diversity in their functionalitypropyl or benzylsulfonic acid ligands) and the perceived lack of batch to batch reproducibility and column longevity; it is apparent that a simple and robust chromatographic characterisation protocol would be extremely useful. This was accomplished by developing a column characterisation procedure which assesses their cation exchange, hydrophobicity and aromatic character.

The robustness of the developed SCX column characterisation protocol was assessed using a factorial design (also called fractional design of experiment, DoE) in which small systematic changes reflecting the expected experimental errors associated with the procedure were explored [12-14]. The retention and selectivity factors were used as responses to create models which highlighted the degree of deviation the systematic changes created from the nominal centre point, i.e. the original method conditions. This data highlighted what variable(s) (i.e. chromatographic operating parameters) were statistically significant and their practical relevance on the result, thus exemplifying which operating parameters must be carefully controlled to maintain a robust column characterisation protocol.

\section{Experimental}

Mobile phase solutions have been prepared gravimetrically to minimise errors associated with volumetrically dispensing solutions. The correct volume of solutions has been weighed out taking into account their densities hence the mobile phase solutions are still classed as v/v.

\section{Chemicals and Reagents}

Water and acetonitrile used were of HPLC grade and supplied by Sigma Aldrich (Poole, UK). All compounds used and the mobile phase additives were supplied by Sigma Aldrich and Fisher Scientific (Loughborough, UK). Phenidine hydrochloride derivatives (see Online resource 1) were synthesised and supplied by Dr. O. B. Sutcliffe (Manchester Metropolitan University, M15GD).

\section{Potassium Dihydrogen Phosphate (100 mM, pH 2.5)}

Potassium dihydrogen phosphate $(6.80 \pm 0.01 \mathrm{~g}$ using a four decimal place balance) was accurately weighed and dissolved in approximately $400 \mathrm{~mL}$ HPLC grade water and mixed. The $\mathrm{pH}$ was then adjusted to 2.5 using orthophosphoric acid. The solution was made up to $500.0 \pm 0.1 \mathrm{~g}$ using a two decimal place balance.

\section{Characterisation Test Mixture}

Stock solutions of benzylamine $\mathrm{HCl}$, nortriptyline $\mathrm{HCl}$, salbutamol sulfate and diphenhydramine $\mathrm{HCl}$ in water were prepared at a nominal concentration of $0.5 \mathrm{mg} \mathrm{mL}^{-1}$. The characterisation test mixture was prepared by mixing 400,100, 200 and $600 \mu \mathrm{L}$ of the stock benzylamine, nortriptyline, salbutamol and diphenhydramine solutions, respectively. Individual stock solutions were found to be stable for up to 1 month if stored at $4{ }^{\circ} \mathrm{C}$, whilst the test mixture was prepared daily and discarded after $24 \mathrm{~h}$.

\section{Liquid Chromatography}

LC separations were performed on a Shimadzu Nexera X2 UHPLC system (Duisburg, Germany) equipped with two binary pumps (LC-30AD) and proportionating valves, degassers (DGU-20A $\mathrm{AR}_{\mathrm{SR}}$ ), autosampler (SIL-30AC), Prominence column oven (CTO-20AC), diode array detector (SPD-M30A) and communication bus module (CBM20A). The software used to control the LC system was LabSolutions (Version 5.86). The robustness evaluation was performed on a Nexera- $i$ series integrated LC using LabSolutions Version 5.90 software.

Unless otherwise stated, the following isocratic LC conditions were employed using a mobile phase as described in "Potassium dihydrogen phosphate $10 \mathrm{mM} \mathrm{pH} 2.5$ in water/acetonitrile $(60: 40 \mathrm{v} / \mathrm{v})$ " section. For a column format of $150 \times 4.6 \mathrm{~mm}$, the following conditions were employed: a flow rate of $1.0 \pm 0.1 \mathrm{~mL} \mathrm{~min}^{-1}$ (for pressure reasons the Supelcosil SCX and the Agilent Bio SCX NP were run at 2 and $0.5 \mathrm{~mL} \mathrm{~min}{ }^{-1}$, respectively), $40 \pm 1{ }^{\circ} \mathrm{C}$, $30 \mu \mathrm{L}$ (for non $150 \times 4.6 \mathrm{~mm}$ columns, the injection volume and flow rate was scaled as appropriate) and detection at $214 \mathrm{~nm}$ (bandwidth $8 \mathrm{~nm}$ ), reference $360 \mathrm{~nm}$ (bandwidth $100 \mathrm{~nm}$ ). All columns were equilibrated with 100 column volumes before running the analysis and after changing the mobile phase conditions. Run times were typically within 45 min.

\section{Potassium Dihydrogen Phosphate $10 \mathrm{mM} \mathrm{pH} 2.5$ in Water/ Acetonitrile $(60: 40 \mathrm{v} / \mathrm{v})$}

$50.0 \pm 0.1 \mathrm{~g}$ of potassium dihydrogen phosphate $(100 \mathrm{mM}$, pH 2.5, see "Potassium dihydrogen phosphate $100 \mathrm{mM}$, $\mathrm{pH} 2.5$ " section) was accurately weighed using a two-place balance. This was added to $250.0 \pm 0.1 \mathrm{~g}$ of water and $157.2 \pm 0.1 \mathrm{~g}(200 \pm 0.13 \mathrm{~mL})$ of $\mathrm{MeCN}$, using a two decimal place balance, and the solution was mixed yielding a potassium dihydrogen phosphate $10 \mathrm{mM} \mathrm{pH} 2.5$ in water/ acetonitrile $(60: 40 \mathrm{v} / \mathrm{v})$ solution. 


\section{Stationary Phases}

All columns were new as supplied by the manufacturer (see Table 1). A Luna SCX column $(150 \times 4.6 \mathrm{~mm}, 100 \AA$ A $5 \mu \mathrm{m})$ was used for the robustness evaluation. Column batch to batch variability was assessed on six different Luna SCX columns packed with three differing base silicas and four differing silanes $(150 \times 4.6 \mathrm{~mm}, 100 \AA$, $5 \mu \mathrm{m})$.

\section{Software and Calculations}

Principal Component Analysis (PCA) was performed using SIMCA (Version 14.1, Umetrics, Umeå, Sweden). The variables within the PCA were all autoscaled to give each variable the same importance. A factorial design was performed using Modde Pro (Version 12.0.1. Umetrics, Umeå, Sweden). The physical/chemical properties of the bases were calculated using Percepta (ACD Toronto, Canada). Student $t$ test analysis was performed in Microsoft Excel. The void volume for the column was determined from the peak apex of a water injection at $214 \mathrm{~nm}$ [15]. This was used to determine the retention factors of benzylamine (B), salbutamol (S), diphenhydramine (D) and nortriptyline (N) and the selectivity factors $(\alpha)$ between $\mathrm{B} / \mathrm{S}, \mathrm{S} / \mathrm{D}, \mathrm{B} / \mathrm{D}, \mathrm{D} / \mathrm{N}$, $\mathrm{S} / \mathrm{N}$ and $\mathrm{B} / \mathrm{N}$ (see Online resource 3 ).

\section{Factorial Design}

The factors evaluated in the DoE are summarised in Table 2, including the different \pm 1 level. The design employed was a $2^{(5-2)}$ fractional factorial design with three centre points to allow an estimate of the reproducibility (see Online resource 2). The factors investigated were selected as the most likely sources of error, where the levels were ascertained to reflect the random variation

Table 2 Operating parameters investigated in the DoE, including the nominal conditions ( 0 level) and the expected deviation ( \pm 1 levels)

\begin{tabular}{llll}
\hline Parameter & -1 Level & 0 Level & +1 Level \\
\hline Column temperature $\left({ }^{\circ} \mathrm{C}\right)$ & 38 & 40 & 42 \\
$\begin{array}{l}\text { Flow Rate }\left(\mathrm{mL} \mathrm{min}^{-1}\right) \\
\begin{array}{l}\text { Potassium phosphate concentration } \\
(\mathrm{mM})\end{array}\end{array}$ & 0.9 & 1 & 1.1 \\
$\mathrm{pH} 100 \mathrm{mM}$ potassium phosphate & 2.4 & 10 & 10.1 \\
MeCN composition $(\% \mathrm{v} / \mathrm{v})$ & 39.9 & 4.5 & 2.6 \\
\hline
\end{tabular}

Table 1 Stationary phase properties as derived from the manufacturers

\begin{tabular}{|c|c|c|c|c|c|c|c|c|}
\hline $\begin{array}{l}\text { SCX phase } \\
\text { description }\end{array}$ & Manufacturer & $\begin{array}{l}\text { Particle } \\
\text { size }(\mu \mathrm{m})\end{array}$ & Pore size $(\AA)$ & $\% \mathrm{C}$ load & $\begin{array}{l}\text { Surface area } \\
\left(\mathrm{m}^{2} \mathrm{~g}^{-1}\right)\end{array}$ & $\begin{array}{l}\text { Binding capac- } \\
\text { ity }\end{array}$ & $\begin{array}{l}\text { Chromato- } \\
\text { graphic Sup- } \\
\text { port }\end{array}$ & $\begin{array}{l}\text { Sulfonic acid } \\
\text { attachment }\end{array}$ \\
\hline Epic & ES Industries & 3 & 120 & $\begin{array}{l}\text { Proprietary } \\
\text { information }\end{array}$ & 230 & $3.00 \mathrm{meq} \mathrm{g}^{-1}$ & Silica & Aryl \\
\hline Inertsil & GL Sciences & 5 & 100 & 14 & 450 & $0.5 \mathrm{meq} \mathrm{g}^{-1}$ & Silica & Propy aryl \\
\hline Biobasic & Thermo & 5 & 300 & 3 & 100 & $0.07 \mathrm{meq} \mathrm{g}^{-1}$ & Silica & Propyl \\
\hline $\begin{array}{l}\text { Poly (2-sulfoe- } \\
\text { thyl asparta- } \\
\text { mide) A }\end{array}$ & Poly LC & 3 & 300 & $\begin{array}{l}\text { Proprietary } \\
\text { information }\end{array}$ & 115 & $400 \mu \mathrm{mol} \mathrm{g}{ }^{-1}$ & $\begin{array}{l}\text { Silica coated } \\
\text { with a } \\
\text { hydrophilic } \\
\text { polymer }\end{array}$ & $\begin{array}{l}\text { Poly (2-sulfoe- } \\
\text { thyl asparta- } \\
\text { mide) }\end{array}$ \\
\hline Agilent Bio & Agilent & 1.7 & Non-porous & $\begin{array}{l}\text { Proprietary } \\
\text { information }\end{array}$ & $\begin{array}{l}\text { Proprietary } \\
\text { information }\end{array}$ & $53 \mathrm{mg} \mathrm{mL}^{-1}$ & $\begin{array}{l}\text { Highly } \\
\text { crosslinked } \\
\text { poly(styrene } \\
\text { divinylb- } \\
\text { enzene) } \\
\text { particles } \\
\text { grafted with } \\
\text { a hydrophilic } \\
\text { polymeric } \\
\text { layer }\end{array}$ & $\begin{array}{l}\text { Bonded to the } \\
\text { hydro- } \\
\text { philic layer } \\
\text { (multiple } \\
\text { ion-exchange } \\
\text { groups per } \\
\text { anchoring) }\end{array}$ \\
\hline Spherisorb & Waters & 5 & 80 & 3 & 220 & $0.006 \mathrm{meq} \mathrm{g}^{-1}$ & Silica & Propyl \\
\hline Luna & Phenomenex & 5 & 100 & 9 & 400 & 0.15 meq g $^{-1}$ & Silica & Aryl \\
\hline Supelcosil & Supelco/Merck & 5 & 120 & 2.4 & 170 & $\begin{array}{l}\text { Proprietary } \\
\text { information }\end{array}$ & Silica & Propyl \\
\hline Partisphere & Avantor & 5 & 100 & $\begin{array}{l}\text { Proprietary } \\
\text { information }\end{array}$ & 210 & $\begin{array}{l}\text { Proprietary } \\
\text { information }\end{array}$ & Silica & Aryl \\
\hline Partisil & Avantor & 5 & 85 & $\begin{array}{l}\text { Proprietary } \\
\text { information }\end{array}$ & 440 & $\begin{array}{l}\text { Proprietary } \\
\text { information }\end{array}$ & Silica & Aryl \\
\hline
\end{tabular}


expected (i.e. at least $3 \times$ the expected standard deviation). Error propagation calculations based on instrument specifications and qualification data were employed in the estimation of standard deviation [16].

Modde Pro software (see "Software and calculations" section) was employed to create and evaluate the factorial designs, which utilised eight experiments with various +1 or -1 levels for the different variables, and three repeat experiments for the central nominal conditions to ascertain the reproducibility of the procedure (see Online resource 2). Different batches of mobile phase were produced for the nominal conditions. The software created random experiments to remove any bias within the results. The DoE study aims to prove the robustness of the method when slight differences in operating parameters are assessed that could be imparted by different instruments, laboratories and operators when performing the experiment. These experiments were performed using pre-mixed mobile phases made up by weight to minimise errors associated with dispensing large quantities of solutions volumetrically.

\section{Results and Discussion}

\section{Selection of the Basic Analytes}

A small range of basic probes was desirable for the column characterisation protocol to rapidly assess the cation exchange capacity, hydrophobicity and potential aromatic character of the SCX phases. To achieve this, the physical chemical diversity (i.e. 11 physical/chemical parameters as determined by Percepta) of 10 potential basic probes $\left(\log \mathrm{D}\right.$ at $\mathrm{pH} 2.5$ range 1.66 to -2.86 , basic nitrogen $p K_{a}$ range $=7.8-10.0$, primary, secondary and tertiary amino functionality, containing various numbers of aromatic rings) was assessed by Principal Component Analysis (PCA). From the resultant PCA score plot (see Online resource 4), four bases (benzylamine, salbutamol, diphenhydramine and nortriptyline) were selected $(\log \mathrm{D}$ at $\mathrm{pH} 2.5$ range 1.66 to -2.49 , basic nitrogen $p K_{a}$ range $=8.8-10.0,1 \times$ primary, $2 \times$ secondary and $1 \times$ tertiary amino functionality). Salbutamol was inversely correlated along the first Principal Component (PC1) to diphenhydramine and nortriptyline and reflected the columns selectivity differences towards analytes with differing hydrophobicity. Diphenhydramine and nortriptyline, despite possessing similar hydrophobicity, were selected as there was a desire to probe the columns' selectivity differences towards secondary and tertiary bases (i.e. steric accessibility). The hydrophilic and primary base, benzylamine, was also selected as it was influenced by PC2 (i.e. the molar volume and polarizability parameters).

\section{Hydrophobicity and Aromatic Character}

It was observed that toluene and propylbenzene failed to be retained on either the Luna or Supelcosil SCX columns (manufacturers state that they contain benzene and propyl sulfonic acid moieties, respectively) at $0-10 \%$ levels of $\mathrm{MeCN}$ levels in the mobile phase, highlighting the low hydrophobicity/aromatic character of these type of columns towards neutral aromatic analytes.

\section{Rationale for the Selection of the LC Conditions and Chromatographic Responses}

\section{$\mathrm{pH}$, Temperature and Buffer Concentration}

To maximise the cation exchange interaction of the sulfonic acid moieties with the basic analytes, a $\mathrm{pH}$ of 2.5 was selected (typically used for the analysis of hydrophilic bases) which would result in the basic nitrogen and the sulfonic acid being fully charged. In addition, $\mathrm{pH} 2.5$ would minimise any contribution from free silanol groups of the base silica towards the phase's cation exchange capacity. An elevated temperature of $40^{\circ} \mathrm{C}$ was selected to minimise differences in oven types [17]. A preliminary one factor at a time (OFAT) study over the temperature range of $36-44{ }^{\circ} \mathrm{C}$ highlighted that temperature had a minimal effect on the two hydrophilic bases (benzylamine and salbutamol, $\Delta k_{\left(44-36^{\circ} \mathrm{C}\right)}=-0.25$ and -0.19 , respectively) whereas the two hydrophobic bases (nortriptyline and diphenhydramine, $\Delta k_{\left(44-36{ }^{\circ} \mathrm{C}\right)}=-0.32$ and -0.41 , respectively) demonstrated a greater reduction in retention as temperature was increased. Potassium phosphate was used as the buffer as this is commonly used in ion exchange chromatography. It was observed that within a buffer concentration range of $1-40 \mathrm{mM}$, retention decreased as expected when the buffer concentration increased. However, there was little effect on selectivity. To obtain rapid analysis, a $10 \mathrm{mM}$ buffer concentration was employed for the column characterisation protocol.

\section{Proportion and Type of Organic in the Mobile Phase}

It was anticipated that the type of organic would not play a major role in determining selectivity as we had shown that the phases possessed minimal hydrophobic interaction towards non-polar analytes. Hence, $\mathrm{MeCN}$ was selected as the organic modifier to reduce the back pressure of the system. The effect of MeCN content on the retention of the four bases (constant buffer strength was maintained) can be seen in Fig. 1. Ammonium formate buffer was used instead of potassium phosphate as the latter would not have been soluble in $80 \% \mathrm{MeCN}$. In contrast to the 


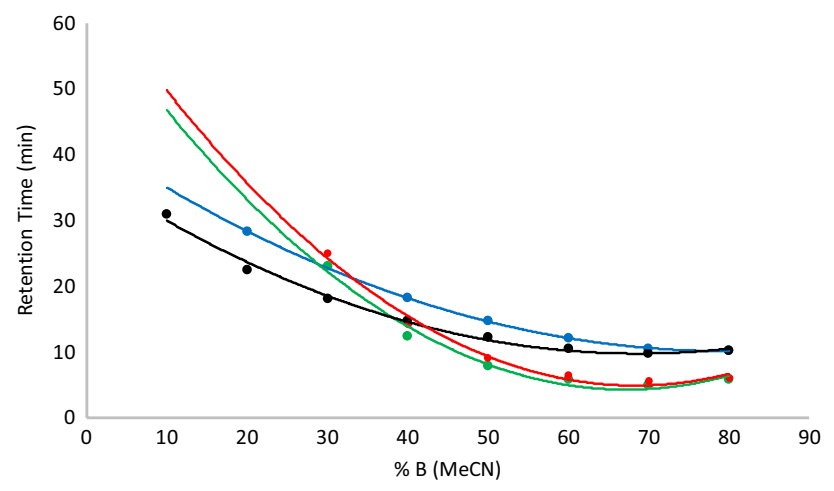

Fig. 1 Effect of $\mathrm{MeCN}(\% \mathrm{v} / \mathrm{v})$ on the retention of the four bases (filled blue circle, benzylamine; filled black circle, salbutamol; filled red circle, diphenhydramine and filled green circle, nortriptyline) in $10 \mathrm{mM}$ ammonium formate $(\mathrm{pH} 2.5)$ on the Luna SCX column at $40{ }^{\circ} \mathrm{C}$

lack of hydrophobic interaction observed between neutral hydrophobic analytes and the SCX phases, the results confirm that hydrophobic interactions are possible due to the hydrophobic spacers between the silica and sulfonic acid moiety as the protonated base is drawn into the stationary phase. Consequently, low levels of organic modifier are typically required in the mobile phase to diminish any hydrophobic interactions [18-20]. The hydrophobic interaction appears to be more pronounced with the hydrophobic bases - diphenhydramine and nortriptyline $(\log \mathrm{D}=0.6$ and 1.66 for, respectively) compared to the polar bases - benzylamine and salbutamol $(\log \mathrm{D}=-2$ and -2.49 for, respectively). For all analytes, as the proportion of $\mathrm{MeCN}$ increases, the retention decreases which is indicative of a hydrophobic interaction contribution to the overall retention of the analytes. At high proportions of $\mathrm{MeCN}$ (i.e. $\approx 70 \% \mathrm{v} / \mathrm{v}$ ), there is minimal hydrophobic interaction and as a consequence the polar bases benzylamine and salbutamol are retained longer. In comparison, at low proportions of $\mathrm{MeCN}$ (i.e. $<50 \%$ ), the hydrophobic bases nortriptyline and diphenhydramine are retained longer. The lower the proportion of $\mathrm{MeCN}$ the greater the hydrophobic bases are retained compared to the polar ones. This result implies a synergistic effect between the ion exchange and hydrophobic retention of hydrophobic bases. Neutral aromatic/hydrophobic compounds do not penetrate the highly polar SCX phase, whereas the hydrophobic bases are drawn into the phase by an electrostatic attraction. Once near the hydrophobic propyl or benzene spacer of the phase, the bases can undergo hydrophobic interactions (the neutral analytes are not drawn into the phase-hence no retention).

For the column characterisation protocol, it was decided to employ a mobile phase of $40 \% \mathrm{MeCN}$ which would promote a mixture of ion exchange and hydrophobic retention.

\section{Rationale Selection of Responses}

Retention factors of the four bases and their selectivity values $\left(\alpha_{\mathrm{B} / \mathrm{S}}, \alpha_{\mathrm{S} / \mathrm{N}}, \alpha_{\mathrm{S} / \mathrm{D}}, \alpha_{\mathrm{B} / \mathrm{N}}, \alpha_{\mathrm{B} / \mathrm{D}}\right.$ and $\left.\alpha_{\mathrm{D} / \mathrm{N}}\right)$ were determined by employing an isocratic mobile phase composition of $10 \mathrm{mM}$ potassium phosphate $(\mathrm{pH} 2.5)$ in $\mathrm{MeCN} /$ water $(40: 60 \mathrm{v} / \mathrm{v})$ at $40{ }^{\circ} \mathrm{C}$ (see Online resource 3). The \%RSD range for the four retention and six selectivity factors for the ten phases were 86-106\% and 19-35\% RSD, respectively. This indicated the highly discriminating nature of these selected chromatographic responses in differentiating between SCX phases.

\section{Principal Component Analysis of the Column Characterisation Results}

The PCA score plot (Fig. 2a) highlights how similar or different the SCX columns are to each other-those located close to each other are more similar whilst those far apart are chromatographically different with respect to their responses. Over $83 \%$ of the variation between the ten columns could be described simply by using two principal components (PC) as shown in Fig. 2a. The score plot indicates that there is a high degree of diversity between the ten phases evaluated suggesting that there would appear to be no chromatographically similar SCX phases hence making the selection of equivalent/"back up" columns difficult/impossible-this was confirmed by comparing their chromatograms in Fig. 3.

The PCA corresponding loading plot (Fig. 2b) illustrates how the chromatographic responses contribute to the two PCs. Chromatographic responses located close to each other have a similar importance for the differentiation of objects (i.e. columns). Comparing the score and loading plot together would suggest that the columns located in the righthand side of the score plot (i.e. close to the retention factors in the loading plot) are highly retentive phases compared to those positioned in the left-hand side. For example, the Epic and Inertsil phases which were located on the right-hand side possessed $k_{\text {benzylamine }}=37.4$ and $30.1, k_{\text {salbutamol }}=20.4$ and $17.2, k_{\text {nortriptyline }}=30.5$ and 17.8 and $k_{\text {diphenhydramine }}=23.4$ and 17.2, respectively. In contrast, the Poly (2-sulfoethylaspartamide) A and Biobasic phases which were located on the lefthand side possessed $k_{\text {benzylamine }}=2.8$ and $1.6, k_{\text {salbutamol }}=2.2$ and $1.3, k_{\text {nortriptyline }}=1.4$ and 1.2 and $k_{\text {diphenhydramine }}=1.4$ and 1.1 , respectively. The observed retentivity is in line with the ion exchange binding capacity quoted by the manufacturers (see Table 1).

To validate the column characterisation protocol, a range of different bases were chromatographed on the 
Fig. 2 a PCA score plot and b PCA loading plot of the ten materials as assessed by the SCX column characterisation protocol. PC1 and PC2 $=50$ and $33 \%$, respectively
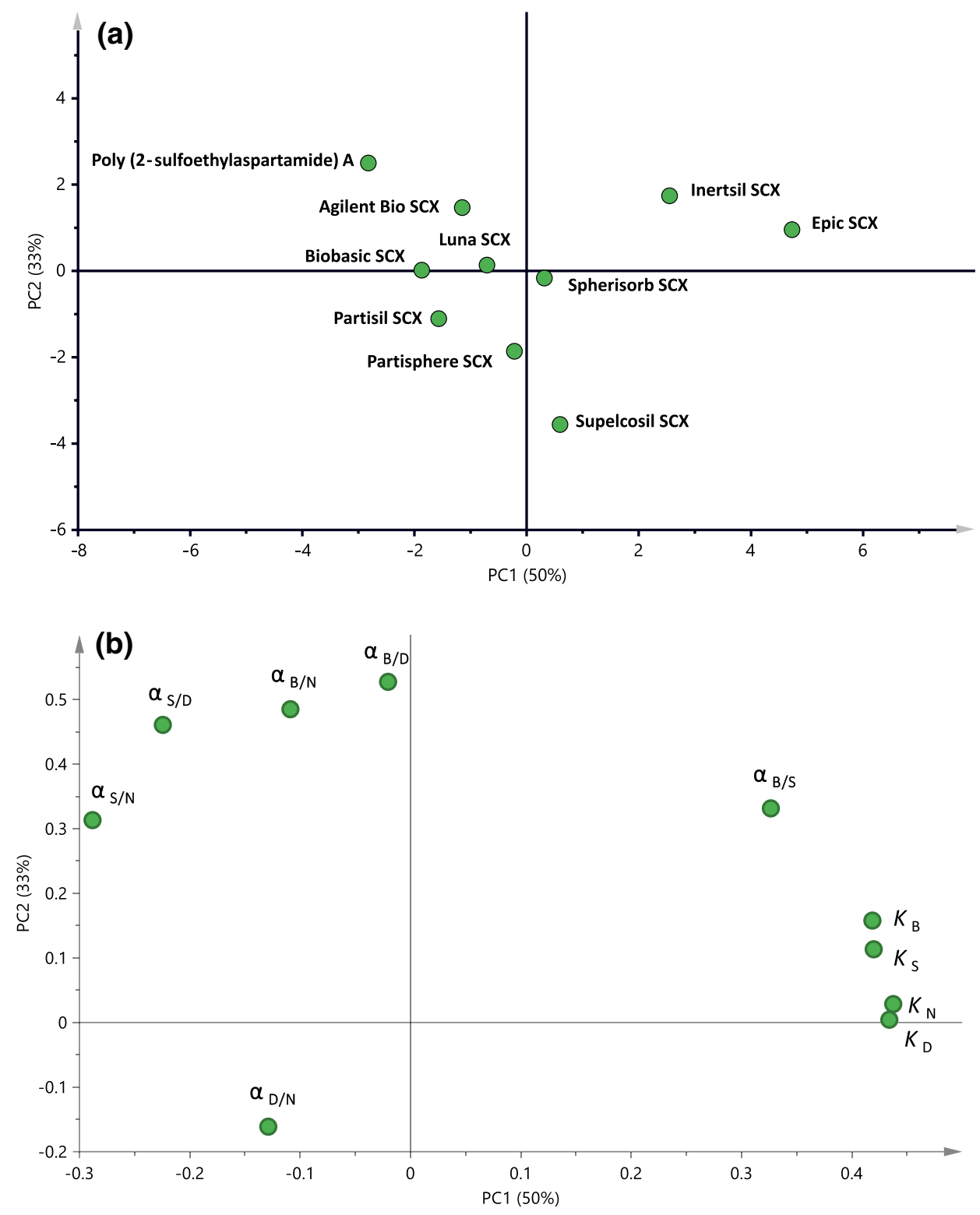

Luna and Supelcosil SCX phases which, from the PCA score plot, should provide large chromatographic selectivity differences (see Figs. 2 and 3). A measurement of chromatographic selectivity $(S)$ between the Supelcosil and Luna phases can be derived from the correlation of the retention time of 18 disparate basic analytes on these two phases chromatographed using the same LC conditions. The selectivity correlations were determined using Eq. 1 [21].

$S=100 \sqrt{1-r^{2}}$

where $r^{2}=$ correlation coefficient between the retention times of the two phases under the specified LC conditions.
$S$ values of 0 and 100 signify columns of equal and orthogonal retention selectivity. An $S$ value of 99 was obtained between the Supelcosil and Luna SCX phases highlighting their complementary chromatographic selectivity (see Fig. 4 and Online resource 1).

\section{Robustness of the SCX Column Characterisation Protocol}

The robustness of the Column Characterisation Protocol was evaluated using a factorial design, to ascertain the influence of operating parameters (including temperature, flow rate, $\mathrm{pH}$ of the potassium phosphate buffer, buffer concentration and the proportion of $\mathrm{MeCN}$ in mobile 
phase) on the chromatographic responses used in the column characterisation protocol.

\section{Rationale for the Factorial Design Limits}

Based on initial OFAT studies and the likely errors associated with the procedure, the following design of experiment (DoE, see Table 2 and "Factorial design" section) was performed on a Luna SCX column which was chosen as it was located fairly close to the origin in the PCA score plot (Fig. 2a) and, therefore, can be considered to have average properties. To minimise errors all mobile phases were prepared gravimetrically but are expressed as v/v. Based on "pH, temperature and buffer concentration" section and the typical errors associated with $\mathrm{pH}$ measurements a $\mathrm{pH}$ range of \pm 0.1 from the nominal was deemed appropriate for the DoE study. The OFAT temperature study (see " $\mathrm{pH}$, temperature and buffer concentration" section) demonstrated little influence on the retention factor of the basic probes over the temperature range of $36-44^{\circ} \mathrm{C}$, in addition, many instrument manufacturers have oven specification limits of $\pm 0.8^{\circ} \mathrm{C}$. However, it has been demonstrated that there are observable differences in column temperature between differing manufacturer's ovens $[22,23]$ hence a temperature range of $\pm 2{ }^{\circ} \mathrm{C}$ from the nominal was deemed appropriate for the DoE study. The error associated with the MeCN content in the mobile phase prepared gravimetrically using a two decimal place balance was calculated to be $\pm 0.1 \mathrm{~g}$ $( \pm 0.13 \mathrm{~mL})$, hence, $a \pm 0.1 \%$ range from the nominal was selected. In comparison, the errors associated with the buffer concentration was selected to be $\pm 0.1 \mathrm{mM}$ assuming a fourplace decimal balance was used for the preparation of the $100 \mathrm{mM}$ stock buffer. Based on typical manufacturer's flow

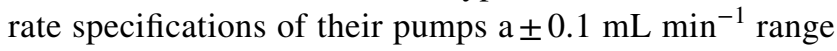
from the nominal was deemed appropriate for the DoE study.

\section{Evaluation of the DoE Results}

Ideally in a robustness test where the levels have been chosen to reflect the experimental noise, both the $R^{2}$ (the percentage of variation of the response explained by the model) and $Q^{2}$ values (the percentage of the variation of the response predicted by the model according to cross-validation and shows how well the model predicts new data) should be low indicating that it is not possible to fit a model [24, 25]. If $R^{2}$ and $Q^{2}$ are low, the selected parameters and levels result in only noise i.e. the method would be robust. In our case, the $R^{2}$ value is close to 0.9 with a low $Q^{2}$ value suggesting that some of the parameters may have statistical significance but the model is poor. The most meaningful evaluation of the robustness is to compare the effect of each parameter and level with the experimental noise estimated by the repeated centre point (see Figs. 5 and 6). If these confidence intervals cover zero the method is robust with respect to that parameter and level evaluated. If the confidence levels do not cross zero then that parameter is statistically significant, however, if the effect is small it might still lack practical importance (the bars in Figs. 5 and 6 correspond to a change from -1 to +1$)$.

Figure 5 clearly demonstrates that the proportion of $\mathrm{MeCN}$, mobile phase $\mathrm{pH}$ and flow rate do not affect the retention factor of basic probes, however, as expected, on increasing the temperature of the analysis and the buffer concentration in the mobile phase retention decreased to a small extent. An increase of $4{ }^{\circ} \mathrm{C}$ or $0.2 \mathrm{mM}$ resulted in a change of the retention factor of less than 0.3 units. Since the range in retention factor between columns is 20 units or more (Online resource 3 ) the increase would correspond to a less than $1.5 \%$ change in retention factor. This was deemed to be of no practical significance for the classification of columns. In comparison, Fig. 6 highlights that the methodology was robust for the selectivity factors between two hydrophilic or hydrophobic probes as they were both affected to approximately the same extent. Whereas, selectivity factors between the hydrophilic/hydrophobic bases increased as temperature and the proportion of $\mathrm{MeCN}$ was increased. An increase of $4{ }^{\circ} \mathrm{C}$ or $0.2 \% \mathrm{MeCN}$ resulted in a change of the selectivity factors of less than 0.006 units. Since the range in selectivity factors between columns is 0.7 units or more (Online resource 3 ), the increase would correspond to a less than $0.9 \%$ change in selectivity factors. This was deemed to be of no practical significance for the classification of columns.

It is recommended that the characterisation protocol operating parameters should be controlled within the following limits, i.e. $\% \mathrm{MeCN} \pm 0.1 \mathrm{v} / \mathrm{v}$, buffer $\mathrm{pH} \pm 0.1$, flow rate $\pm 0.1 \mathrm{~mL} \mathrm{~min}^{-1}$, temperature $\pm 1^{\circ} \mathrm{C}$ and buffer concentration $\pm 0.1 \mathrm{mM}$. The robustness testing highlighted that the tolerances for the operating parameters were all acceptable. Despite being deemed statistically significant, the practical relevance of the temperature, buffer concentration and proportion of $\mathrm{MeCN}$ in the mobile phase limits on the retention and selectivity factors was negligible when the range of retention and selectivity factors which were determined for the columns was taken into consideration.

\section{Reproducibility of the SCX Column Characterisation protocol}

Inter-day and intra-day experiments were performed using four different batches of stock potassium dihydrogen phosphate (100 mM, pH 2.5) using on line mixing and a Luna SCX column. Intra-day and inter-day variability indicated that there was no statistical difference between the means of the results 

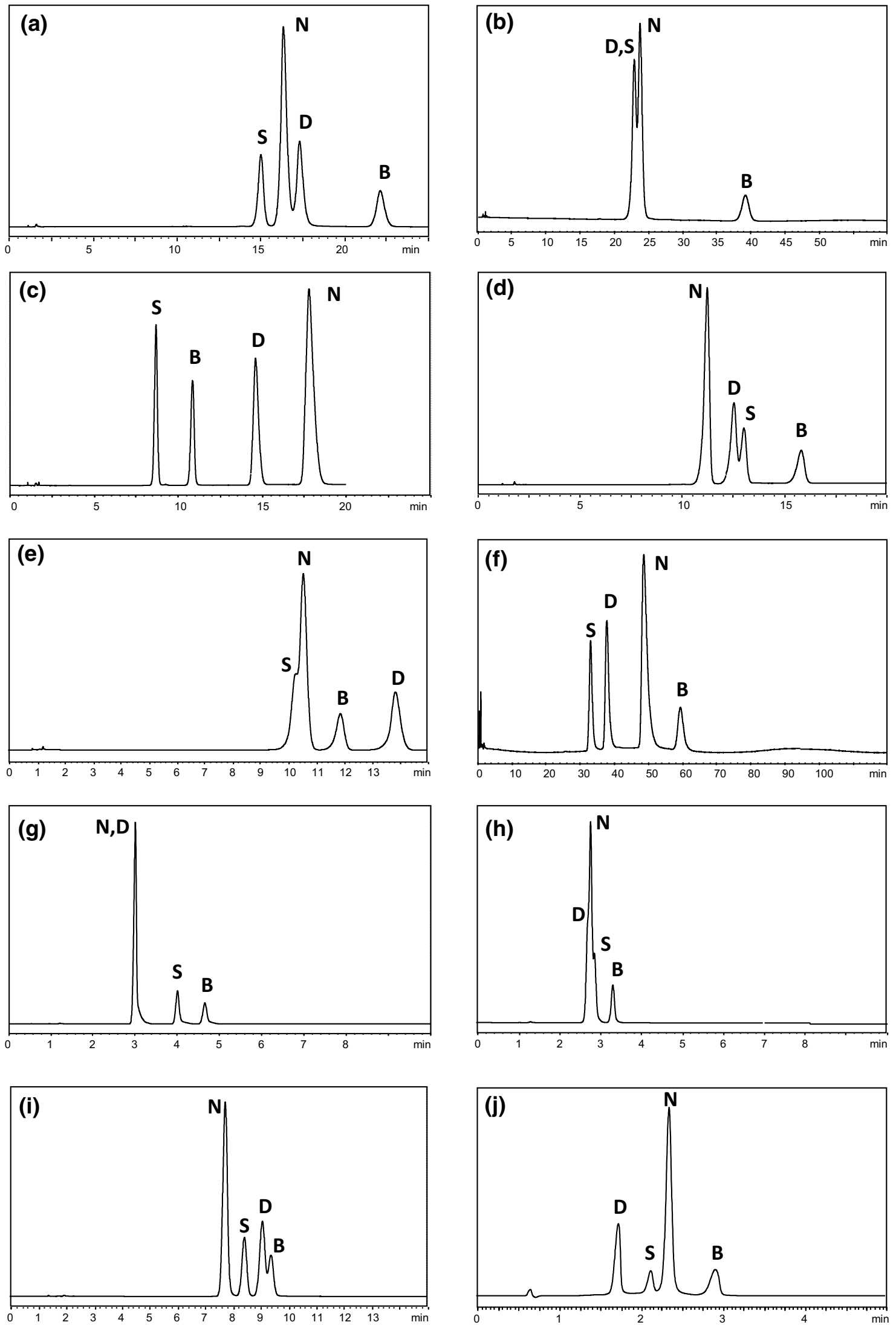
4Fig. 3 Chromatograms of the test mixture. a Spherisorb SCX; b Inertsil SCX; c Supelcosil SCX; d Luna SCX; e Partisphere SCX; f Epic SCX; g Poly [2-sulfoethylaspartamide] A; h Biobasic SCX; i Partisil SCX and $\mathbf{j}$ Agilent Bio SCX. Peak assignment: $\mathrm{N}=$ nortriptyline; $\mathrm{D}=$ diphenhydramine; $\mathrm{S}=$ salbutamol and $\mathrm{B}=$ benzylamine. LC conditions as specified in "Liquid chromatography" section were employed

amongst the two sets of results (Student $t$ test, $P=0,05$ ). It was also demonstrated that there was no statistical difference between mobile phases $(\mathrm{v} / \mathrm{v})$ prepared volumetrically or gravimetrically (Student $t$ test, $P=0.05$ ), however, it was recommended that mobile phases should be made up gravimetrically to minimise preparation errors for the column characterisation protocol.

\section{SCX Column Batch to Batch Variability}

Column batch to batch variability was assessed using five Luna columns on the same day using the same instrument and mobile phase. Three columns were of the same batch whilst three columns were prepared from differing base silica and silane. The batch to batch observations can be seen encircled within the PCA score plot (see Online resource 5a) where the scatter observed is due to the batch to batch variation (retention factor $\%$ RSD for the four bases for the same and differing batches of the Luna material was $<1.6$ and $2.6 \%$, respectively). The results are also in keeping with previous batch to batch studies performed on other RP columns using various protocols [13, 26-28]. This highlights that any deviation between differing phases within the PCA score plot is caused by their selectivity differences, thus it is feasible to distinguish SCX stationary phases which are chromatographically similar or dissimilar using this approach. As seen in the PCA score plot (see Online resource 5a and b), there were some variations between the different Luna columns. The red circles correspond to columns of the same batch and the yellow circles for

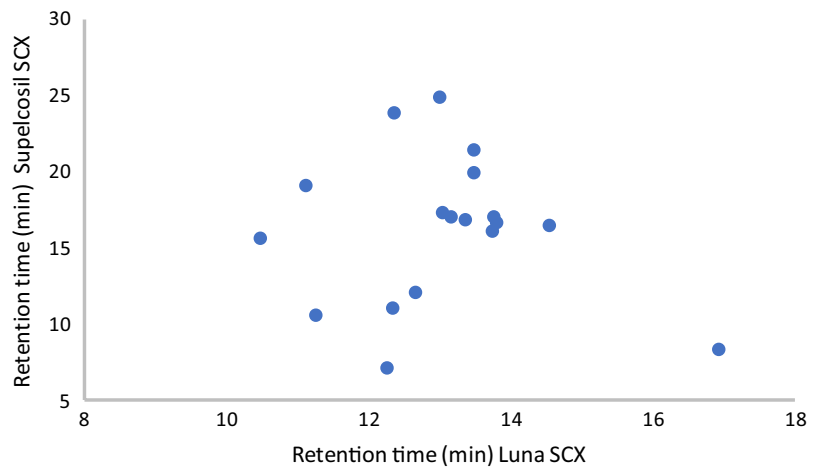

Fig. 4 Comparison of the retention times of 18 basic analytes chromatographed using the characterization conditions-Supelcosil

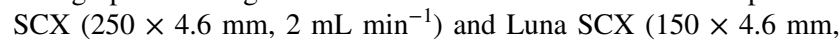
$1 \mathrm{~mL} \mathrm{~min}^{-1}$ ) phases. LC conditions as specified in "Liquid chromatography" section were employed. 20 and $30 \mu \mathrm{L}$ of the individual basic analytes $\left(0.5 \mathrm{mg} \mathrm{mL}^{-1}\right.$ in water) were injected onto the 150 and $250 \mathrm{~mm}$ columns, respectively

columns between different batches. These variations were not significant in the overall view of the score plot between all phases. However, it is impossible to extrapolate these batch to batch results to other SCX phases. The green circles correspond to the experiments in the DoE evaluation. The variability in the DoE results is more than the batch to batch variability. The robustness of the results generated from the column characterisation protocol was demonstrated to be acceptable and comparable results were obtained for the same Epic column run in two different laboratories, differing operators, using differing batches of mobile phases and LC instrumentation (see Online resource 5). In an extension of this work, we have been able to correlate characterisation results to the ageing of an SCX material and its suitability for the analysis of a 39 amino acid peptide analysed using similar LC conditions (i.e. low $\mathrm{pH}, 40^{\circ} \mathrm{C}$ and $\mathrm{MeCN}$ ).
Fig. 5 Coefficient plots of retention factors. Bar assignment: Blue $=$ benzylamine; orange $=$ salbutamol; green $=$ nortriptyline and red $=$ diphenhydramine
Retention factors

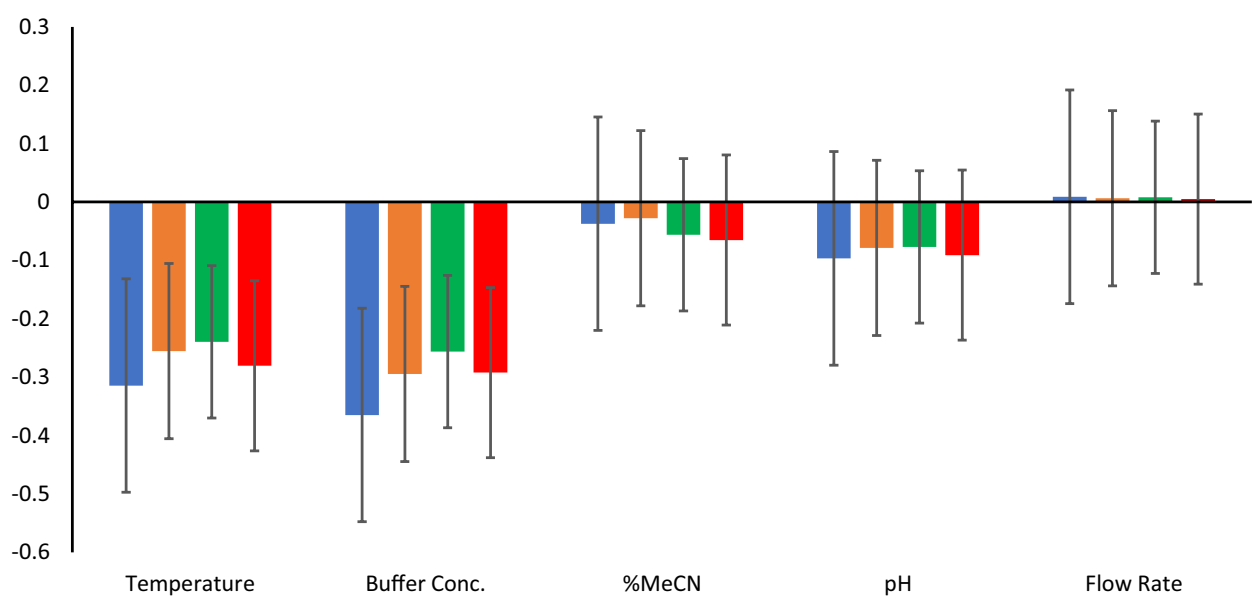


Fig. 6 Coefficient plots of selectivity factors. Bar assignments: blue $=\alpha_{\mathrm{B} / \mathrm{S}} ;$ orange $=\alpha_{\mathrm{S} / \mathrm{D}}$; green $=\alpha_{\mathrm{N} / \mathrm{D}} ;$ red $=\alpha_{\mathrm{S} / \mathrm{N}} ;$ purple $=\alpha_{\mathrm{B} / \mathrm{D}}$ and grey $=\alpha_{\mathrm{B} / \mathrm{N}}$
Selectivity factors

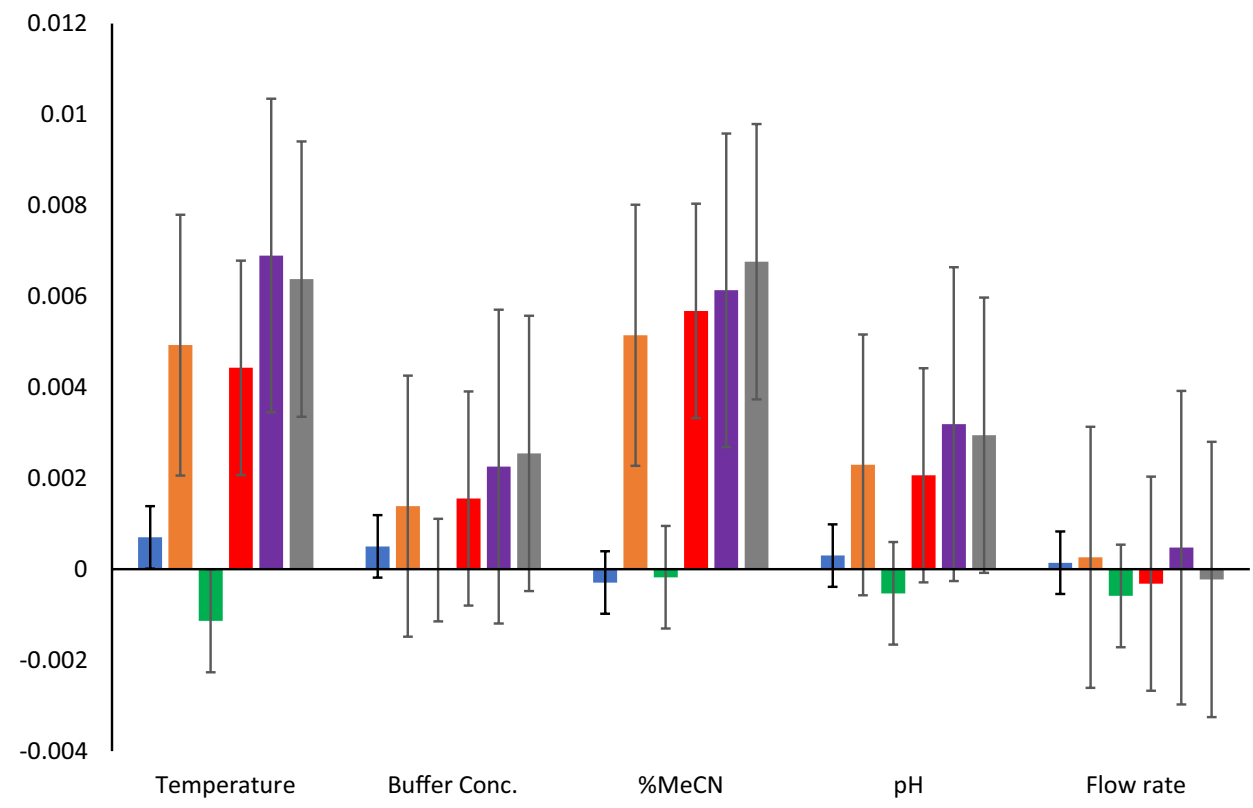

\section{Conclusions}

A simple characterisation protocol for the evaluation of a range of SCX phases (suitable for the analysis of small molecular weight bases) is described. The protocol was demonstrated via design of experiment principles to be reproducible and robust within the operating parameters proposed. The protocol permits the assessment of the individual ion exchange and hydrophobic character of SCX materials as well as their combined mixed mode retention capability. The synergistic effect between ion exchange and hydrophobicity retention on basic analytes could also be observed. This was highlighted by the switch in retention between the hydrophilic and hydrophobic bases as a function of the proportion of MeCN employed in the mobile phase. The diverse chromatographic properties of a range of SCX materials was demonstrated by applying PCA to the column characterisation results. The PCA score plots for the first and second principal components described $83 \%$ of the variability within the dataset. The analysis highlighted the high diversity of SCX materials making the selection of "back-up" columns extremely difficult from the columns tested. The chromatographic selectivity differences observed between SCX materials in the PCA analysis was validated in the analysis of a range of different basic analytes. The protocol has been used to assess batch to batch variability and column aging of a SCX column for its suitability in the analysis of a 39 amino acid peptide using similar $\mathrm{LC}$ conditions (i.e. low $\mathrm{pH}, 40^{\circ} \mathrm{C}$ and $\mathrm{MeCN})$. It is proposed that more relevant $\mathrm{LC}$ conditions (i.e. intermediate $\mathrm{pH}$, ambient temperature and low
MeCN containing mobile phases) and large molecule probes will be required to characterise the increasing number of non-porous SCX phases reaching the market specifically for the analysis of biomolecules.

Acknowledgements With thanks to Shimadzu for the supply of the Nexera X2 instrument, Avantor, ES Industries, Phenomenex and Supelco for the supply of the stationary phases, Dr O. B. Sutcliffe (Manchester Metropolitan University, M15GD) for kindly synthesising and supplying the individual phenidine hydrochloride derivatives, Umetrics for providing the SIMCA and Modde Pro software, ACD/ Labs for providing the Percepta software. Dr Andrew Alpert (PolyLC Inc., USA) for helpful discussions at HPLC2018 regarding the findings of this work.

Funding Part of this work was funded by Novo Nordisk A/S, Shimadzu Ltd UK, and AstraZeneca Macclesfield.

\section{Compliance with ethical standards}

Conflict of interest The authors declare that they have no competing interests.

Open Access This article is licensed under a Creative Commons Attribution 4.0 International License, which permits use, sharing, adaptation, distribution and reproduction in any medium or format, as long as you give appropriate credit to the original author(s) and the source, provide a link to the Creative Commons licence, and indicate if changes were made. The images or other third party material in this article are included in the article's Creative Commons licence, unless indicated otherwise in a credit line to the material. If material is not included in the article's Creative Commons licence and your intended use is not permitted by statutory regulation or exceeds the permitted use, you will need to obtain permission directly from the copyright holder. To view a copy of this licence, visit http://creativecommons.org/licenses/by/4.0/. 


\section{References}

1. Wilson NS, Nelson MD, Dolan JW, Snyder LR, Wolcott RG, Carr PW (2002) Column selectivity in reversed-phase liquid chromatography I. A general quantitative relationship. J. Chromatogr. A 961:171-193

2. Euerby MR, Petersson P (2003) Chromatographic classification and comparison of commercially available reversed-phase liquid chromatographic columns using principal component analysis. J Chromatogr A 994:13-36

3. U.S. Pharmacopeial Convention. http://apps.usp.org/app/USPNF /columnsDB.html. Accessed 23 Oct 2018

4. Hydrophobic Subtraction Model. http://www.hplccolumns.org/ about/index.php. Accessed 17 May 2019

5. ACD Column Selection Database. https://www.acdlabs.com/resou rces/freeware/colsel/. Accessed 23 Oct 2018

6. Kawachi Y, Ikegami T, Takubo H, Ikegami Y, Miyamoto M, Tanaka N (2011) Chromatographic characterization of hydrophilic interaction liquid chromatography stationary phases: hydrophilicity, charge effects, structural selectivity, and separation efficiency. J Chromatogr A 1218:5903-5919

7. West C, Lemasson E, Bertin S, Hennig P, Lesellier E (2016) An improved classification of stationary phases for ultra-highperformance supercritical fluid chromatography. J Chromatogr A 1440:212-228

8. Flanagan RJ, Harvey EJ, Spencer EP (2001) HPLC of basic drugs on microparticulate strong cation-exchange materials-a review. Forensic Sci Int 121:97-102

9. Trass M, Orlowicz S. Analysis of Metformin $\mathrm{HCl}$ using a LUNA SCX Ion-exchange HPLC column per the USP monograph. Application TN-1202. https://az621941.vo.msecnd.net/docum ents/839da259-ad70-4140-b56e-c132ff339cfd.pdf. Accessed 25 Oct 2019

10. Ashiru DAI, Patel R, Basit AW (2007) Simple and universal HPLC-UV method to determine cimetidine, ranitidine, famotidine and nizatidine in urine: application to the analysis of ranitidine and its metabolites in human volunteers. J Chromatogr B 860:235-240

11. Liu H, Wang H, Sunderland VB (2005) An isocratic ion exchange HPLC method for the simultaneous determination of flucloxacillin and amoxicillin in a pharmaceutical formulation for injection. $\mathbf{J}$ Pharm Biomed Anal 37:395-398

12. Dejaegher B, Heyden YV (2007) Ruggedness and robustness testing. J Chromatogr A 1158:158-167

13. Petersson P, Euerby MR (2005) An evaluation of the robustness of the Tanaka characterization protocol for reversed-phase liquid chromatography columns. J Sep Sci 28:2120-2129

14. Guidelines for Industry (2005) Text on Validation of Analytical Procedures, ICH-Q2A. https://www.ich.org. Accessed 22 May 2019

15. Petersson P, Boateng BO, Field JK, Euerby MR (2018) A practical approach to modelling of reversed-phase liquid chromatographic separations: advantages, principles, and possible pitfalls. LCGC Eur 31:120-143

16. Miller JC, Miller JN (1993) Statistics for Analytical Chemistry, 3rd edn. Ellis Horwood Limited, Chichester

17. Field JK, Euerby MR, Petersson P (2019) Investigation into reversed phase chromatography peptide separation systems Part II: an evaluation of the robustness of a protocol for column characterisation. J Chromatogr A 1603:102-112

18. Holm A, Estorbra E, Mihailova A, Karaszewski B, Lundanes E, Greibrokk T (2005) Combined solid-phase extraction and 2D LC-MS for characterization of the neuropeptides in rat-brain tissue. Anal Bioanal Chem. 382:751-759

19. Mant CT, Byars A, Ankarlo S, Jiang Z, Hodges RS (2018) Separation of highly charged $(+5$ to +10$)$ amphipathic $\alpha$-helical peptide standards by cation-exchange and reversed-phase high-performance liquid chromatography. J Chromatogr A 1574:60-70

20. Burke TW, Mant CT, Black JA, Hodges RS (1989) Strong cationexchange high-performance liquid chromatography of peptides: effect of non-specific hydrophobic interactions and linearization of peptide retention behaviour. J Chromatogr 476:377-389

21. Neue UD, O'Gara JE, Mendez A (2006) Selectivity in reversedphase separations influence of the stationary phase. J Chromatogr A $1127: 161-174$

22. Fallas MM, Hadley M, McCalley DV (2009) Practical assessment of frictional heating effects and thermostat design on the performance of conventional ( 3 micron and 5 micron) columns in reversed-phase high-performance liquid chromatography. J Chromatogr A 1216:3961-3969

23. Wolcott RG, Dolan JW, Snyder LR, Bakalyar SR, Arnold MA, Nichols AJ (2000) Control of column temperature in reversedphase liquid chromatography. J Chromatogr A 869:211-230

24. Box GEP, Hunter JS, Hunter WG (2005) Statistics for experimenters: design, innovation, and discovery, 2nd edn. Wiley, New Jersey

25. Montgomery DC, Peck EA, Vining GG (2012) Introduction to linear regression analysis, 5th edn. Wiley, New Jersey

26. Kele M, Guiochon G (1999) Repeatability and reproducibility of retention data and band profiles on reversed-phase liquid chromatography columns: I. Experimental protocol. J Chromatogr A $830: 41-54$

27. Kele M, Guiochon G (1999) Repeatability and reproducibility of retention data and band profiles on reversed-phase liquid chromatography columns. III. Results obtained with Kromasil C18 columns. J Chromatogr A 855:423-453

28. Kele M, Guiochon G (2000) Repeatability and reproducibility of retention data and band profiles on reversed-phase liquid chromatography columns. IV. Results obtained with Luna C18 (2) columns. J Chromatogr A 869:181-209

Publisher's Note Springer Nature remains neutral with regard to jurisdictional claims in published maps and institutional affiliations. 